\title{
Editorial: Loosen the shackles of legislation
}

During the past 50 years there have been some remarkable advances in medical science; who would have dreamt that Dolly the Sheep could lead the way to the cloning of human beings - a scary thought!

During this time the quality of life has improved enormously for everyone with better living conditions for all. The end result is that today's pensioner can expect to live to the age of 80-85; whereas after the Second World War the expectation of life was less than 70. There has been talk of the life expectancy figure rising to 150 in years to come, but let us not venture there, as this is unthinkable where pension legislation is concerned!

In the same period, increases in real earnings and the advances in technology have resulted in an almost full employment scenario in the UK for both men and women. Indeed, many couples find complete fulfilment in their jobs with the consequence that they opt not to have a family. The resultant decrease in birthrate will, in time, reduce the population.

The combination of increased expectation of life and the reduced birthrate means that the support ratio (the number of citizens of working age over the number of citizens of pension age) is projected to fall to around two by the year 2050, whereas it was five in 1950.

The reduction in this ratio has long-term consequences for the UK state pay-as-you-go pension scheme. The fundamental question is whether present and future working populations are prepared to pay for the retired population. It is acknowledged that there would be a general reluctance to pay increased national insurance contributions; hence cost savings have been introduced.

The UK government decided that the best way of reducing the cost is to continue to charge contributions that will increase each year in line with earnings. However, the state pension will increase each year only in line with the increase in prices. At present the state pension is some 17 per cent of national average earnings and it is anticipated that it will reduce to 10 per cent of the same earnings over the course of the next 25 years.

As not all employees are in occupational pension schemes it is acknowledged that employees require private pension provision to supplement the reducing state scheme. Hence, the government has introduced stakeholder pensions from April 2001.

It is not compulsory for employers to contribute to these schemes. Therefore the employee is very much on his own; financially responsible for determining the level of contributions that are paid each month, choosing the investment medium and then, at retirement, responsible for choosing the type of pension. 
On retirement (or at age 75 at the latest, under UK legislation) an annuity has to be purchased from a life insurance company. The terms of the annuity contract reflect the economic conditions prevailing in the country at the time that the annuity is purchased; however, that contract remains in force for some 20-30 years, during which time the economic conditions will change significantly. Unfortunately the annuitant has to live with the consequences of that contract - taken out many years before. The main repercussion is the change in the rate of inflation and this impacts on the annuitant's ability to maintain the existing lifestyle.

Index-linked annuities mitigate the consequences of inflation; however, they are unreasonably expensive due to the government's debt repayment schedule and the MFR requirements.

It is commendable, from the point of view of debt management, to reduce the national debt; however, the consequence must be examined from the other side: the pensioner. In the changing economic environment from the time that the annuity was purchased the pensioner is being penalised.

The more financially astute investor uses income drawdown up to age 75 and thereafter purchases an annuity. In this scenario, the government should now take the next step and remove the ridiculous upper age of 75 that is imposed for the purchase of an annuity. If a person is capable of arranging and looking after his or her own affairs up to age 75 there is no logical reason why they suddenly become incapable at age 75 plus.
Indeed, it is remarkable that the chancellor has not removed the age limit. Under present legislation, when an annuitant dies with an annuity, the balance of the annuity estate reverts to the life office. Abolishing the age 75 legislation would mean that it would be taxed before being distributed by the trustees to the beneficiaries.

If the government is serious about its citizens looking after themselves in retirement, there are two things it should do:

- ensure that there is an adequate supply of index-linked gilt stock — abolish the age 75 annuity rule.

Retirement can be a wonderful time in life - who does not, at some point, long for the life of Victor Meldrew whose daily worries do not extend further than gardening, snoozing and The Times crossword! Of course, in order to lead this carefree life of security in retirement, one needs an adequate income. It would be no fun being an Alf Garnett, miserable and having to scrimp and save. The government has it within its power, however, to make retirement more financially secure. Thus, loosening the shackles of pension legislation should be top of its agenda over the next 12 months to ensure that there are more Victors and fewer Alfs out there among the pensioners of the UK.

Ian M. Aitken Editorial Board 